\title{
Evaluation of PD-L1 Expression in Tumor Tissue of Patients with Lung Carcinoma and Correlation with Clinical and Demographic Data
}

\author{
Gustavo Dix Junqueira Pinto, ${ }^{1}$ Luciano de Souza Viana, ${ }^{2,3}$ \\ Cristovam Scapulatempo Neto, ${ }^{3,4}$ and Sérgio Vicente Serrano ${ }^{1,5}$ \\ ${ }^{1}$ Department of Medical Oncology, Barretos Cancer Hospital, Barretos, SP, Brazil \\ ${ }^{2}$ Department of Oncology, Marcio Cunha Hospital, Fundação São Francisco Xavier, Ipatinga, MG, Brazil \\ ${ }^{3}$ Post Graduation Program in Oncology, Barretos Cancer Hospital, Barretos, SP, Brazil \\ ${ }^{4}$ Pathology, Clinicas Oncologicas Integradas, Rio de Janeiro, RJ, Brazil \\ ${ }^{5}$ Barretos School of Health Sciences (FACISB), Barretos, SP, Brazil
}

Correspondence should be addressed to Gustavo Dix Junqueira Pinto; gustavodjp@gmail.com

Received 13 April 2016; Revised 20 July 2016; Accepted 18 August 2016

Academic Editor: Mario Clerici

Copyright (C) 2016 Gustavo Dix Junqueira Pinto et al. This is an open access article distributed under the Creative Commons Attribution License, which permits unrestricted use, distribution, and reproduction in any medium, provided the original work is properly cited.

\begin{abstract}
Lung cancer is the leading world cause of cancer-related death, in both genders, and smoking is the main etiological factor. The discovery of immune checkpoints corroborates the hypothesis that ligands presented in tumors modulate the mechanisms of carcinogenesis and the immune activity of tumor microenvironment. Among the most studied coregulatory molecules, PD1 (programmed cell death 1) and its ligand PD-L1 (programmed cell death 1 ligand 1) are noteworthy. The present study aims to enhance the understanding of the tumor microenvironment of lung cancer patients who underwent surgery, by means of analysis of PD-L1 expression in tumor cells and in intratumoral immune cells (IICs). It was found that PD-L1 expression was more frequent in tumor cells than in IICs. Collective analysis by Tissue Microarray Assay (TMA) for PD-L1 expression in tumor cells and IICs did not reproduce the findings for separate individual analysis of tumor tissues. Patients with past history of smoking were more likely to express PD-L1 in tumor cells than those who never smoked. Patients with past history of smoking were less likely to have PD-L1 positive IICs compared to those who had never smoked. The immunohistochemical expression of PD-L1 in tumor cells and IICs did not correlate with survival.
\end{abstract}

\section{Introduction}

Lung cancer remains the leading cause of cancer death worldwide, for both men and women. Over half of people diagnosed with lung cancer die within one year of diagnosis and the 5 -year survival is less than $18 \%$ [1].

In Brazil, according to 2016 estimates of INCA (National Cancer Institute), the incidence rate for tracheal, bronchus, and lung tumors will be 17330 new cases $(8.1 \%$ of total) for men and 10890 cases (5.3\% of total) for women [2].

Despite major advances in the personalized medicine, non-small-cell lung cancer is still related to poor prognosis.
Until recently, non-small-cell lung cancer was considered a nonimmunogenic tumor, but there is now evidence highlighting the integral role played by both inflammatory and immunological responses in lung carcinogenesis [3]. The discovery of immune checkpoints corroborates the hypothesis that ligands presented in tumors modulate the mechanisms of carcinogenesis and the immune activity of tumor microenvironment. New strategies in immunotherapy are targeting immune-modulating mechanisms that help tumor cells defend themselves against the immune system. Immune checkpoints are inhibitory pathways that maintain self-tolerance and protect the peripheral tissues by modulating the immune responses [4]. 
Recent studies show that tumor cells and antigen presenting cells modify tumor microenvironment through PD1 receptor activities involving their ligands, PD-L1 and PDL2 $[5,6]$. PD-1 is a type I membrane protein composed of 268 amino acids which belongs to T-cell CD28/B7 family and is encoded by PDCD1 gene $[7,8]$. It has an extracellular $\mathrm{IgV}$ domain, followed by a transmembrane region, and an intracellular tail, which contains two phosphorylation sites $[9,10]$ and is expressed on the surface of activated T cells, B cells, and macrophages [10].

Programmed cell death 1 ligand 1 (PD-L1) or B7 homolog 1 (B7-H1) is a type I transmembrane protein encoded by the CD274 gene [11].

The PD-1 function occurs primarily in peripheral tissues, where the $\mathrm{T}$ cells can contact their immunosuppressive ligands PD-L1 (B7-H1) and PD-L2 (B7-DC), which are expressed by tumor cells, stromal cells, or both [12-15]. It has been shown that inhibition of PD-1/PD-L1 interaction can exacerbate in vitro $\mathrm{T}$ cell response and mediate antitumor activity in preclinical models $[14,16]$.

More than that, PD-L1 expression may also vary according to different tumor microenvironments [17] and even to clinical and demographic data.

One recent study showed that PD-L1 expression was not associated with gender, histology, differentiation status, or lymph node metastasis. However, PD-L1 expression was increased in stage III NSCLC compared with stage I/II [18].

Other studies showed that PD-L1 expression was significantly associated with smoking [19-21], gender, higher tumor grade, advanced $\mathrm{T}$ status, advanced $\mathrm{N}$ status, advanced stage [19], and histology [22].

The role of PD-L1 expression neither as a prognostic nor as a predictive factor is controversial, being suggested in several studies $[8,23,24]$. Other studies do not confirm these findings $[25,26]$.

Indeed, recently, the KEYNOTE-001 trial of pembrolizumab (a humanized antibody that targets the programmed cell death 1 receptor) for advanced NSCLC showed a significantly favourable survival in patients with that PDL1 expression greater than $50 \%$ in comparison to those with expression lower than $50 \%$ [27].

PD-L1 seems to be a mutable biomarker, with variable expression patterns related to heterogeneity in different areas within primary or metastatic lesions.

Histopathological material aging or the interval between tissue collection and treatment may also influence PD-L1 expression [28-30].

Positivity criteria for PD-L1 expression (machinery, antibodies, and cutoff) are not standardized yet and that certainly may contribute for all these discrepancies.

This study attempts to elucidate PD-L1 expression in lung tumor microenvironment. Possibly it may help to understand different clinical outcomes in lung cancer and establish more effective therapeutic measures.

\section{Materials and Methods}

2.1. Study Population. Tumor tissue samples and data were obtained from 177 cases. These patients underwent surgical resection of primary lung cancer between 2003 and 2014 at Barretos Cancer Hospital, Brazil. H\&E stained sections were reviewed by a pathologist (CSN) and histological subtyping was assessed using the current World Health Organisation 2015 classification. Staging was undertaken according to the 7th edition AJCC tumor, node, metastasis (TNM) classification. The ethical use of human tissue for research was approved by the Institutional Review Board, and the design of this study followed the principles of the Declaration of Helsinki and also complied with the principles of good clinical practice.

2.2. Inclusion Criteria. Inclusion criteria include patients older than 18 years of both genders, diagnosed with nonsmall-cell lung cancer (adenocarcinoma, adenosquamous carcinoma, and squamous cell carcinoma), who underwent pneumonectomy, lobectomy, segmentectomy, or nodulectomy with available slides and paraffin blocks for histopathological analysis in the Pathology Department of Barretos Cancer Hospital.

2.3. Exclusion Criteria. Exclusion criteria include inappropriate histopathological material by either poor quality or shortage due to its use in other studies and patients with a current diagnosis of another primary malignancy in any location of the body other than nonmelanoma skin cancer or in situ carcinoma of the cervix.

2.4. PD-L1 Expression. PD-L1 immunohistochemistry membranous expression was assessed in TMA (Tissue Microarray Assay) with 2 cores of $1 \mathrm{~mm}$ in diameter of each tumor and also the expression was evaluated in whole tissue section of the same tumors (individual analysis).

2.5. TMA Blocks and Slides Construction. TMA blocks were made with MTA I (Manual Tissue Arrayer) device (Estigen, Tartu, Estonia), according to manufacturer's specifications. TMA and all the paraffin blocks were sectioned with $4 \mu$ thick and the sections were transferred to positively charged glass slides.

At least one section per paraffin block was stained with hematoxylin-eosin in order to confirm the histology and to certify of tumor tissue availability in the slides by a pathologist and another slide was submitted to PD-L1 immunohistochemistry test.

2.6. Immunohistochemistry. Four micra thick sections (TMA and whole tissue sections) were dewaxed at $80^{\circ} \mathrm{C}$ for $20 \mathrm{~min}$ utes and then were transferred to Ventana BenchMark Ultra Autostainer (Ventana, Tucson, AZ, USA). Antigen retrieval was performed using Ventana Cell Conditioning solution 1 (pH: 8.5) for 64 minutes at $97^{\circ} \mathrm{C}$. Anti-PD-L1 antibody (ab58810, Abcam, Cambridge, MA, USA) at titration of $1: 25$ was incubated for 60 minutes at $36^{\circ} \mathrm{C}$. The detection of antigen antibody reaction was performed using UltraView DAB Universal Detection kit (Ventana, Tucson, AZ, USA). Strong membranous trophoblastic staining in the placenta was used as positive control. Tissue expression of PD-L1 was categorized dichotomically into negative $(<5 \%$ membranous 
tumor cells expression) or positive ( $\geq 5 \%$ membranous tumor cells expression) [31] and also in groups according to the percentage of stained cells and staining intensity for a better sample description. The $\mathrm{PD}$-L1 positive intratumoral immune cells (IICs) were graded as absent, $1+$ (present until 10\% of tumor surface), $2+$ (present in 11-50\% of tumor extension), and $3+$ (present in more than $50 \%$ of tumor surface). Also, for statistical purposes PD-L1 expression was graded as present and absent.

2.7. Statistics. Data were described on the average, standard deviation, minimum, maximum, and quartiles for quantitative variables and frequency tables for qualitative variables. The agreement between the collective analysis technique or TMA (tissue microarray) and individual analysis was done using the Kappa coefficient to assess the reproducibility.

The correlation between clinical and demographic characteristics and PD-L1 expression in tumor cells and IICs was determined using the chi-square test (or Fisher's exact test) for the qualitative characteristics. To check the overall association between covariates and PD-L1 marker, those that had lower $p$ value than 0.2 in the previous test were selected and subsequently adjusted into a logistics multiple regression model. For modeling, one feature (variable) was removed each time by prioritizing those with higher $p$ value, up to a set of significant variables.

For overall survival, the time between diagnosis and death for any reason (which is the event of interest) or last objective information of individuals who have not died yet was considered. To compare each feature and check the list of features with survival (one at each time), simple Cox regression was used. For joint evaluation between variables, those with $p$ value less than 0.2 were selected in simple analysis and adjusted in multiple Cox regression model. Then, modeling was continued as the same description in the logistic regression. To estimate the overall survival curve for PD-L1 expression the Kaplan-Meier method was used.

For survival analysis only overall survival was considered, because it is a retrospective study and there was no standardization in the follow-up of these patients in the past. In this study we considered the statistical significance of 0.05 and SPSS 21.0 software was used for statistical analysis.

\section{Results}

3.1. Demographic Data. In regard to demographic characteristics, as seen in Table 1, most patients were over 60 years old (96 cases; 54.2\%), male (111 cases; 62.7\%), white (140 cases; 79.1\%), ECOG (Eastern Cooperative Oncology Group performance status) 0 (86 cases; $48.6 \%$ ), with reported history of smoking (79 cases; $44.6 \%$ ), and with no history of alcohol abuse (96 cases; $54.2 \%$ ).

3.2. Clinical Data. The most common histological type was adenocarcinoma (115 cases, 65\%) with II degree of differentiation (81 cases; 45.8\%). Most of tumors had TNM Classification of Malignant Tumours lower than III. Stages I and II were observed in 62 patients (35\%) and 53 patients (29.9\%), respectively. Lobectomy was performed in 147 cases
TABLE 1: Demographic characteristics.

\begin{tabular}{lccc}
\hline Variable & Category & $N$ & $(\%)$ \\
\hline \multirow{2}{*}{ Age } & $<60$ years & 81 & 45.8 \\
& $>60$ years & 96 & 54.2 \\
\hline \multirow{2}{*}{ Sex } & Female & 66 & 37.3 \\
& Male & 111 & 62.7 \\
\hline \multirow{3}{*}{ Ethnicity } & White & 140 & 79.1 \\
& Non-white & 32 & 18.1 \\
& Ignored & 5 & 2.8 \\
\multirow{4}{*}{ ECOG } & 0 & 86 & 48.6 \\
& 1 & 46 & 26 \\
& Other & 6 & 3.38 \\
\multirow{4}{*}{ Smoking } & Ignored & 39 & 22.02 \\
& Absent & 39 & 22 \\
& Active & 57 & 32.2 \\
& Past & 79 & 44.6 \\
& Ignored & 2 & 1.1 \\
\hline \multirow{3}{*}{ Alcohol consumption } & No & 96 & 54.2 \\
& Active & 45 & 25.4 \\
& Past & 18 & 10.2 \\
& Ignored & 18 & 10.2 \\
\hline
\end{tabular}

ECOG: Eastern Cooperative Oncology Group performance status.

TABLE 2: Clinical data.

\begin{tabular}{lccc}
\hline Variable & Category & $N$ & $(\%)$ \\
\hline \multirow{3}{*}{ Histological type } & Adenocarcinoma & 115 & 65 \\
& Squamous cell carcinoma & 57 & 32.2 \\
& Other & 5 & 2.8 \\
\hline \multirow{3}{*}{ Tumor grade } & Grade I & 5 & 2.8 \\
& Grade II & 81 & 45.8 \\
& Grade III & 50 & 28.2 \\
TNM staging & Ignored & 41 & 23.2 \\
\hline \multirow{3}{*}{ Surgery type } & I & 62 & 35 \\
& II & 53 & 29.9 \\
& III & 43 & 24.3 \\
& IV & 19 & 10.7 \\
\hline \multirow{3}{*}{ Adjuvant radiotherapy } & Nodule extraction & 4 & 2.3 \\
& Segmentectomy & 12 & 6.8 \\
& Lobectomy & 147 & 83.1 \\
& Pneumonectomy & 14 & 7.9 \\
\hline & Nystemic treatment & 121 & 68.4 \\
& Yes & 55 & 31 \\
& Neoadjuvant chemotherapy & 21 & 11.9 \\
& Adjuvant chemotherapy & 34 & 19.2 \\
& Chemotherapy + radiotherapy & 3 & 1.7 \\
& Ignored & 1 & 0.6 \\
\hline
\end{tabular}

TNM staging: TNM Classification of Malignant Tumours.

(83.1\%). Adjuvant chemotherapy was performed in 34 cases (19.2\%) (Table 2). 
TABLE 3: PD-L1 expression in conventional histological slides (individual analysis).

\begin{tabular}{|c|c|c|c|c|}
\hline Cell type & Evaluation method & Graduation & $N$ & $\%$ \\
\hline \multirow{5}{*}{ Tumor cell } & \multirow{5}{*}{ Intensity } & Absence & 97 & 54.8 \\
\hline & & Weak & 52 & 29.3 \\
\hline & & Moderate & 16 & 9 \\
\hline & & Strong & 1 & 0.6 \\
\hline & & Missing & 11 & 6.2 \\
\hline \multirow{5}{*}{ Tumor cell } & \multirow{5}{*}{ Percentage ( 3 categories) } & Absence & 97 & 54.8 \\
\hline & & Up to $10 \%$ & 6 & 3.4 \\
\hline & & From $11 \%$ to $50 \%$ & 33 & 18.6 \\
\hline & & More than 50\% & 30 & 16.9 \\
\hline & & Ignored & 11 & 6.2 \\
\hline \multirow{3}{*}{ Tumor cell } & \multirow{3}{*}{ Percentage ( 2 categories) } & Positive & 67 & 37.9 \\
\hline & & Negative & 99 & 55.9 \\
\hline & & Ignored & 11 & 6.2 \\
\hline \multirow{5}{*}{ Intratumoral immune cells } & \multirow{5}{*}{ Intensity } & Absence & 123 & 69.5 \\
\hline & & Weak & 25 & 14.1 \\
\hline & & Moderate & 15 & 8.5 \\
\hline & & Strong & 3 & 1.7 \\
\hline & & Ignored & 11 & 6.2 \\
\hline \multirow{5}{*}{ Intratumoral immune cells } & \multirow{5}{*}{ Percentage ( 3 categories) } & Absence & 123 & 69.5 \\
\hline & & Up to $10 \%$ & 3 & 1.7 \\
\hline & & From $11 \%$ to $50 \%$ & 15 & 8.5 \\
\hline & & More than 50\% & 25 & 14.1 \\
\hline & & Ignored & 11 & 6.2 \\
\hline \multirow{3}{*}{ Intratumoral immune cells } & \multirow{3}{*}{ Percentage ( 2 categories) } & Positive & 43 & 24.3 \\
\hline & & Negative & 123 & 69.5 \\
\hline & & Ignored & 11 & 6.2 \\
\hline
\end{tabular}

Positive: more than 5\% stained cells.

Negative: less than 5\% stained cells.

Ignored: staining problems preventing classification into positive or negative.

3.3. PD-L1 Expression in TMA and Whole Tissue Section. PD-L1 was expressed in tumor cells and in IICs. Tumor cells had coarse chromatin, increased nuclei with irregular nuclear membrane, and abundant cytoplasm with ill-defined borders. However, intratumoral immune cells had loose chromatin, smaller fold nuclei without atypia, and variable cytoplasm, sometimes with dendritic expansions (Table 3).

In Figures 1 and 2, there are photomicrographs of PDL1 immunohistochemical expression in conventional histological slides in tumor cells and antigen presenting cells, respectively.

In Figure 3 there are photomicrographs of CD-68 immunohistochemical expression in IICs of non-small-cells lung cancer.

Table 4 contains the results of PD-L1 expression by immunohistochemistry in TMA slides (collective analysis). Positive expression is observed in 58 cases $(32.8 \%)$ in tumor cells and in 35 cases (19.8\%) of IICs, that is, higher expression in tumor cells.

3.4. Immunohistochemical Agreement of PD-L1 Expression in Individual Analysis (Whole Section) versus Collective Analysis (TMA). As noted in Table 5, there was a fair agreement with
Kappa index of 0.307 ( $p<0.001)$ when the immunohistochemical expression of PD-L1 in tumor cells in conventional histological slides (individual analysis) and TMA slides (collective analysis) was evaluated. Similar results were observed with PD-L1 expression in IICs in conventional histological slides (individual analysis) and IICs slides (collective analysis) with Kappa index of $0.328(p<0.001)$.

Once the immunohistochemical expression of PD-L1 was not reproducible between TMA and whole tissue sections, all the analyses (univariate and multivariate) of correlation between PD-L1 expression and covariates (clinical data and demographic and other biomarkers) considered PD-L1 expression in whole tissue section.

3.5. Association of PD-L1 Expression with Demographic Data: Univariate Analysis. As noted in Table 6, patients whose tumors showed positive PD-L1 expression in tumor cells were mostly former smokers (36 cases; $55.4 \%$ ) or active smokers (20 cases; $30.8 \%$ ) with $p$ value $=0.044$.

As seen in Table 7, the correlation between PD-L1 expression in IICs and demographic data was not statistically significant. 


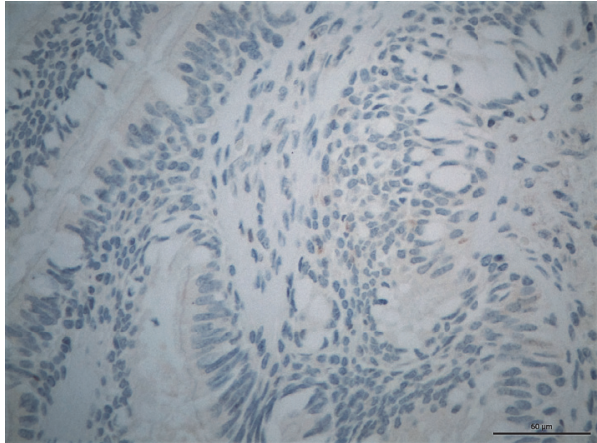

(a)

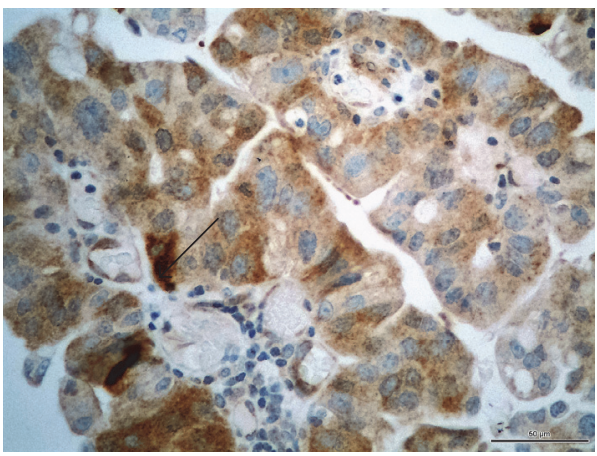

(c)

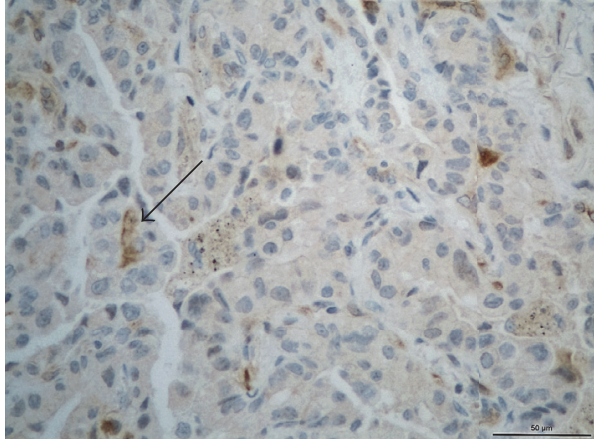

(b)

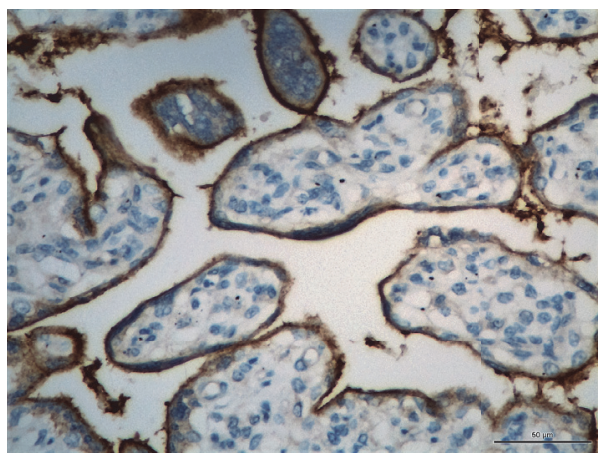

(d)

FIGURE 1: Photomicrographs of PD-L1 immunohistochemical expression in lung cancer tumor cells (magnification/scale bar: 400x/50 $\mu$ ). (a) Absence of PD-L1 expression; (b) negative PD-L1 expression ( $<5 \%$ of stained cells); (c) positive PD-L1 expression ( $\geq 5 \%$ stained cells); (d) Positive Control with placental tissue. Arrows show positive staining cells.

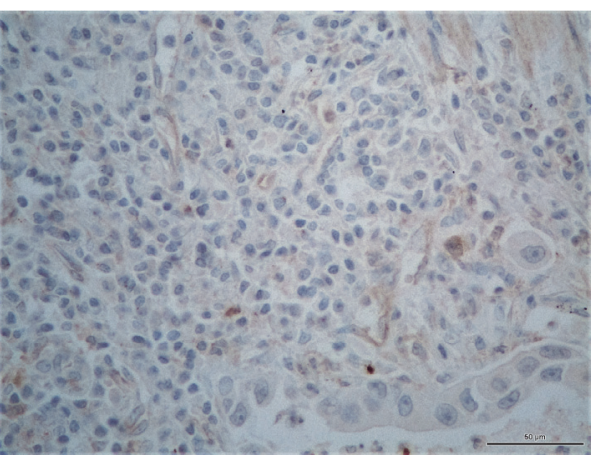

(a)

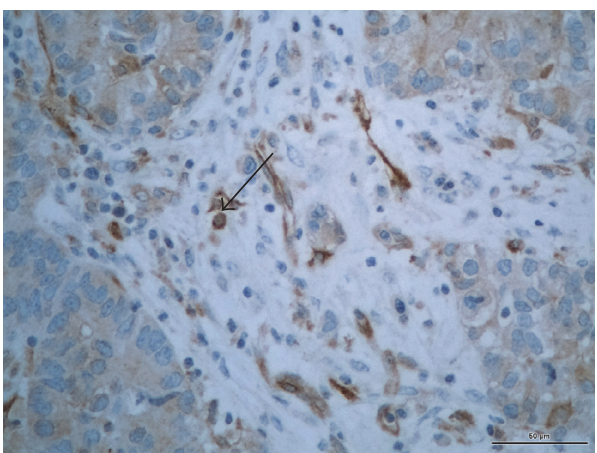

(c)

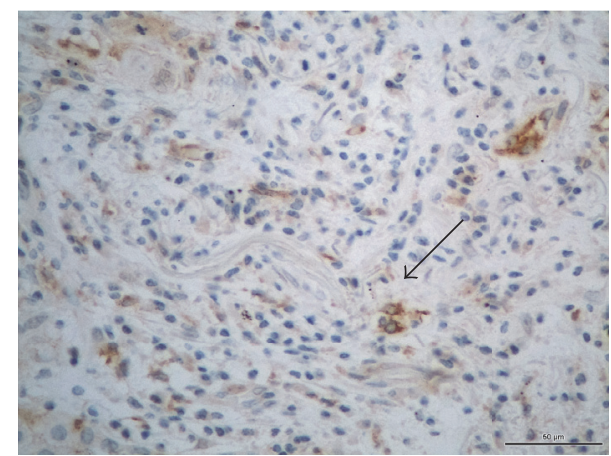

(b)

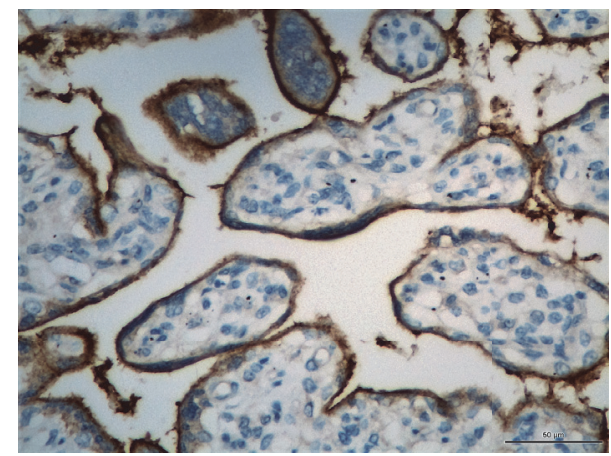

(d)

FIGURE 2: Photomicrographs of PD-L1 immunohistochemical expression in IICs in non-small-cells lung cancer (magnification/scale bar: $400 \mathrm{x} / 50 \mu$ ). (a) Absence of PD-L1 expression; (b) focal PD-L1 expression ( $<5 \%$ of tumor surface); (c) diffuse PD-L1 expression ( $>5 \%$ of tumor surface). Observe the dendritic cytoplasm of some cells; (d) Positive Control. Arrows show positive staining cells. 
TABLE 4: PD-L1 expression in TMA slides (collective analysis).

\begin{tabular}{|c|c|c|c|c|}
\hline Cell type & Evaluation method & Graduation & $N$ & $\%$ \\
\hline \multirow{5}{*}{ Tumor cell } & \multirow{5}{*}{ Intensity } & Absence & 99 & 55.9 \\
\hline & & Weak & 38 & 21.5 \\
\hline & & Moderate & 16 & 9 \\
\hline & & Strong & 4 & 2.3 \\
\hline & & Ignored & 20 & 11.3 \\
\hline \multirow{5}{*}{ Tumor cell } & \multirow{5}{*}{ Percentage (3 categories) } & Absence & 99 & 55.9 \\
\hline & & Up to $10 \%$ & 0 & 0 \\
\hline & & From $11 \%$ to $50 \%$ & 1 & 0.6 \\
\hline & & More than 50\% & 57 & 32.2 \\
\hline & & Ignored & 20 & 11.3 \\
\hline \multirow{3}{*}{ Tumor cell } & \multirow{3}{*}{ Percentage ( 2 categories) } & Positive & 58 & 32.8 \\
\hline & & Negative & 99 & 55.9 \\
\hline & & Ignored & 20 & 11.3 \\
\hline \multirow{5}{*}{ Intratumoral immune cells } & \multirow{5}{*}{ Intensity } & Absence & 122 & 68.9 \\
\hline & & Weak & 24 & 13.6 \\
\hline & & Moderate & 6 & 3.4 \\
\hline & & Strong & 5 & 2.8 \\
\hline & & Ignored & 20 & 11.3 \\
\hline \multirow{5}{*}{ Intratumoral immune cells } & \multirow{5}{*}{ Percentage (3 categories) } & Absence & 122 & 68.9 \\
\hline & & Up to $10 \%$ & 4 & 2.3 \\
\hline & & From $11 \%$ to $50 \%$ & 5 & 2.8 \\
\hline & & More than 50\% & 26 & 14.7 \\
\hline & & Ignored & 20 & 11.3 \\
\hline \multirow{3}{*}{ Intratumoral immune cells } & \multirow{3}{*}{ Percentage ( 2 categories) } & Positive & 35 & 19.8 \\
\hline & & Negative & 122 & 68.9 \\
\hline & & Ignored & 20 & 11.3 \\
\hline
\end{tabular}

Positive: more than $5 \%$ stained cells.

Negative: less than $5 \%$ stained cells.

Missing: staining problems preventing classification into positive or negative.

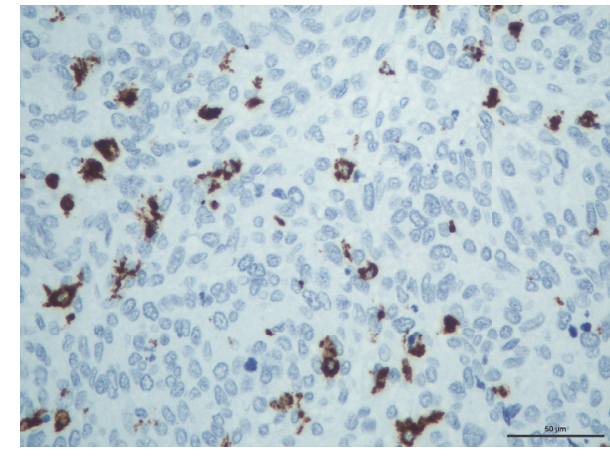

(a)

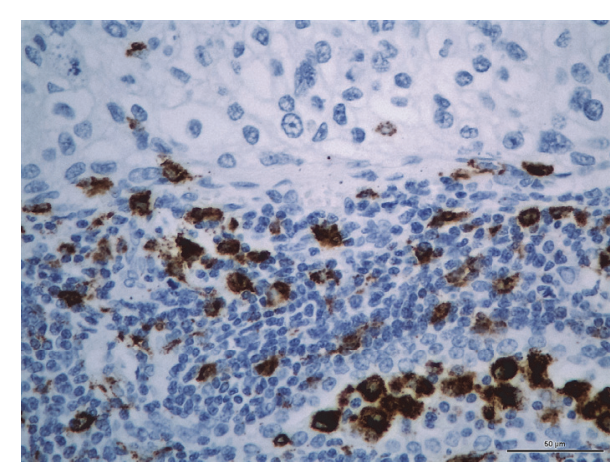

(b)

FIGURE 3: Photomicrographs of CD-68 immunohistochemical expression in IICs in non-small-cells lung cancer (magnification/scale bar: $400 \mathrm{x} / 50 \mu$ ). (a) Isolated IICs in a tumor area. (b) Positive CD-68 expression in a cluster of inflammatory cells.

3.6. Correlation of PD-L1 Expression with Clinical Data. As seen in Table 8 , the correlation between PD-L1 expression in tumor cells and clinical data was not statistically significant.

According to Table 9, among patients whose tumors had positive PD-L1 expression in IICs, most of them presented histologic type adenocarcinoma (35 cases; $81.4 \%$ ) with statistical significance $(p$ value $=0.022)$.

3.7. Correlation of PD-L1 Expression with Clinical and Demographic Data: Multivariate Analysis. Patients with smoking history were more likely to present positive PD-L1 expression 
TABLE 5: Immunohistochemical agreement of PD-L1 expression in individual analysis versus collective analysis considering cell type.

\begin{tabular}{lccc}
\hline Cell type & Kappa & Standard error & $p$ value \\
\hline IICs & 0.328 & 0.089 & $<0.001$ \\
Tumor cells & 0.307 & 0.079 & $<0.001$ \\
\hline
\end{tabular}

in tumor cells when compared to patients who had never smoked $(\mathrm{OR}=3.356 ; 95 \% \mathrm{CI} 1.368$ to $8.230 ; p$ value $=0.008)$ (Table 10).

After logistic regression, smoking was the only variable that remained significant related to $\mathrm{PD}-\mathrm{Ll}$ expression in antigen presenting cells.

Patients with smoking history were less likely to present tumors with positive PD-L1 expression in IICs when compared to patients who had never smoked $(\mathrm{OR}=0.383$; $95 \%$ confidence interval from 0.162 to 0.908 ; and $p$ value $=0.029$ ). The chance of positive PD-L1 expression in intratumoral immune cells was also lower for patients with active smoking when compared to patients who had never smoked but without statistical significance ( $O R=0.525 ; 95 \%$ CI 0.212 to 1.297 ; and $p$ value $=0.169)($ Table 11$)$.

3.8. Survival Curves Analysis according to PD-L1 Expression. The median overall survival of patients included in this study was 45 months (95\% CI 33.23 to 56.83). Considering PDL1 expression in tumor cells of conventional histological slides (individual analysis), there was a higher median overall survival for patients with tumors that had positive PDL1 expression; however this difference was not statistically significant: 98.75 months (95\% CI 21.26 to 176.24) versus 41.51 months (95\% CI 30.05 to 52.98 ) with $p$ value $=0.254$. Also, there was no statistically significant difference in the median overall survival when comparing PD-L1 expression in IICs: 49.50 months (95\% CI 23.37 to 75.64 ) for patients with positive PD-L1 expression versus 41.51 months (95\% CI 29.99 to 53.04) in patients with negative $\mathrm{PD}-\mathrm{L} 1$ expression with $p$ value $=0.795$ (Figures 4 and 5).

\section{Discussion}

4.1. PD-L1 Expression Findings. According to this study, the frequency of PD-L1 expression in tumor cells was 37.9\% of total cases, a little less than a recently published study that showed $53.1 \%$ of positivity [32], although the same antibodies and platforms have been used. There is a bias when comparing positivities related to different studies. There are different platforms (DAKO and VENTANA) to evaluate PDL1 expression and different antibodies (28-8, 22C3, SP263, SP142, and MIH1, among others).

This evaluation can occur in different ways: continuous distribution and proportion of PD-L1 positive cells at any intensity [27], percentage expression (immunohistochemistry score) regardless of its intensity (more than $1 \%$ of stained cells: score 1, more than $5 \%$ stained cells: score 2 , and more than $10 \%$ stained cells: score 3) [33], a combined score displaying a percentage for each intensity [34] by degree in membrane and/or cytoplasmic staining (e.g., Aqua

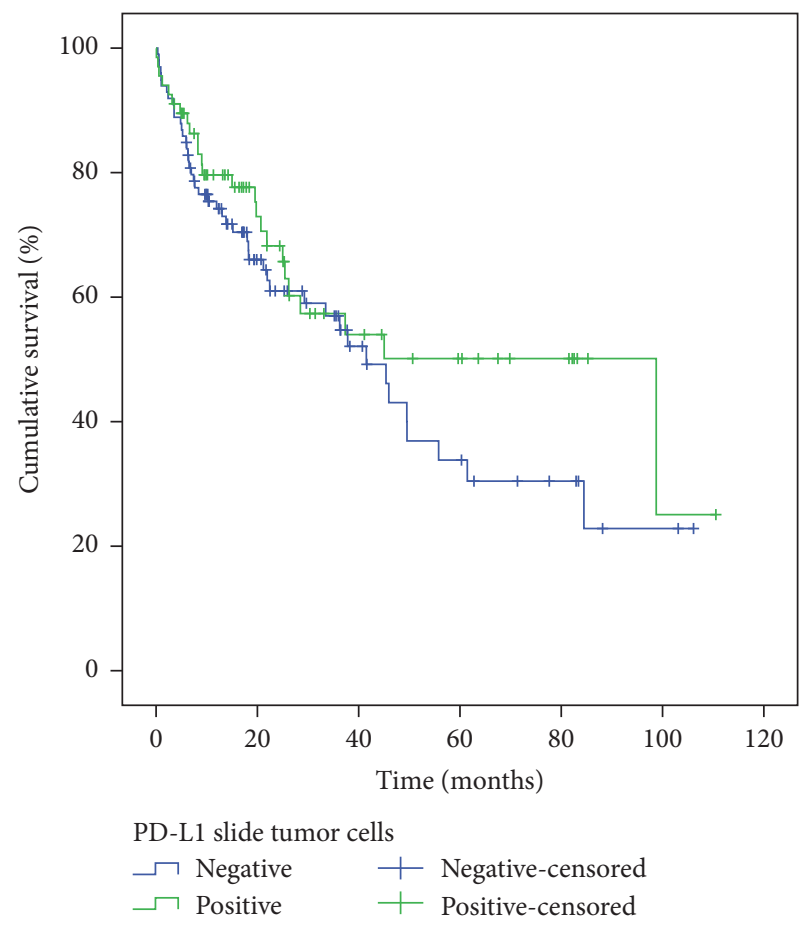

FIGURE 4: Overall survival according to PD-L1 expression in tumor cells. $x$-axis: time after diagnosis in months. $y$-axis: percentage of patients alive (total of 177 patients).

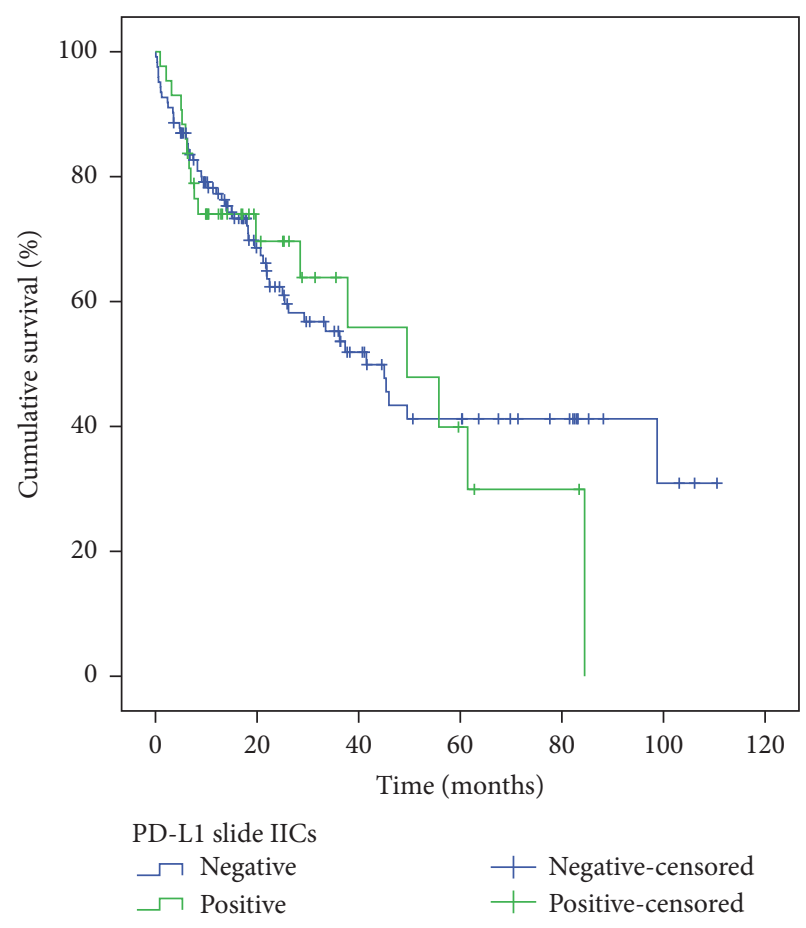

FIgURE 5: Overall survival according to PD-L1 positivity in IICs. $x$ axis: time after diagnosis in months. $y$-axis: percentage of patients alive (total of 177 patients).

Fluorescent Techniques), and protein concentration in Tissue Microarray Assay [35]. 
TABLE 6: PD-L1 expression in tumor cells and demographic data.

\begin{tabular}{|c|c|c|c|c|c|c|}
\hline \multirow{2}{*}{ Variable } & \multirow{2}{*}{ Categories } & \multicolumn{2}{|c|}{ Negative } & \multicolumn{2}{|c|}{ Positive } & \multirow{2}{*}{$p$ value } \\
\hline & & $N$ & $(\%)$ & $N$ & $(\%)$ & \\
\hline \multirow{2}{*}{ Age } & $<60$ & 43 & 43.4 & 30 & 44.8 & \multirow{2}{*}{0.864} \\
\hline & $>60$ & 56 & 56.6 & 37 & 55.2 & \\
\hline \multirow{2}{*}{ Gender } & Female & 39 & 39.4 & 21 & 31.3 & \multirow{2}{*}{0.289} \\
\hline & Male & 60 & 60.6 & 46 & 68.7 & \\
\hline \multirow{2}{*}{ Race } & Non-white & 18 & 18.8 & 11 & 16.7 & \multirow{2}{*}{0.734} \\
\hline & White & 78 & 81.2 & 55 & 83.3 & \\
\hline \multirow{2}{*}{ ECOG } & 0 & 48 & 62.3 & 31 & 70.5 & \multirow{2}{*}{0.367} \\
\hline & 1 & 29 & 37.7 & 13 & 29.5 & \\
\hline \multirow{3}{*}{ Smoking } & No & 29 & 29.3 & 9 & 13.8 & \multirow{3}{*}{0.044} \\
\hline & Active & 31 & 31.3 & 20 & 30.8 & \\
\hline & Former & 39 & 39.4 & 36 & 55.4 & \\
\hline \multirow{3}{*}{ Alcohol consumption } & No & 57 & 63.3 & 34 & 58.6 & \multirow{3}{*}{0.312} \\
\hline & Active & 25 & 27.8 & 14 & 24.1 & \\
\hline & Former & 8 & 8.9 & 10 & 17.2 & \\
\hline
\end{tabular}

ECOG: Eastern Cooperative Oncology Group performance status.

TABLE 7: PD-L1 expression in IICs and demographic data.

\begin{tabular}{|c|c|c|c|c|c|c|}
\hline \multirow{2}{*}{ Variable } & \multirow{2}{*}{ Categories } & \multicolumn{2}{|c|}{ Negative } & \multicolumn{2}{|c|}{ Positive } & \multirow{2}{*}{$p$ value } \\
\hline & & $N$ & (\%) & $N$ & (\%) & \\
\hline \multirow{2}{*}{ Age } & $<60$ & 50 & 40.7 & 23 & 53.5 & \multirow{2}{*}{0.144} \\
\hline & $>60$ & 73 & 59.3 & 20 & 46.5 & \\
\hline \multirow{2}{*}{ Gender } & Female & 41 & 33.3 & 19 & 44.2 & \multirow{2}{*}{0.202} \\
\hline & Male & 82 & 66.7 & 24 & 55.8 & \\
\hline \multirow{2}{*}{ Race } & Non-white & 21 & 17.6 & 8 & 18.6 & \multirow{2}{*}{0.888} \\
\hline & White & 98 & 82.4 & 35 & 81.4 & \\
\hline \multirow{2}{*}{ ECOG } & 0 & 57 & 64.8 & 22 & 66.7 & \multirow{2}{*}{0.845} \\
\hline & 1 & 31 & 35.2 & 11 & 33.3 & \\
\hline \multirow{3}{*}{ Smoking } & No & 23 & 19 & 15 & 34.9 & \multirow{3}{*}{0.084} \\
\hline & Active & 38 & 31.4 & 13 & 30.2 & \\
\hline & Former & 60 & 49.6 & 15 & 34.9 & \\
\hline \multirow{3}{*}{ Alcohol consumption } & No & 67 & 60.9 & 24 & 63.2 & \multirow{3}{*}{0.934} \\
\hline & Active & 29 & 26.4 & 10 & 26.3 & \\
\hline & Former & 14 & 12.7 & 4 & 10.5 & \\
\hline
\end{tabular}

ECOG: Eastern Cooperative Oncology Group performance status.

There is no standardized cutoff for positivity. Some studies have used $1 \%, 5 \%, 50 \%$, or more to consider positive PD-L1 expression [36].

Therefore, it becomes extremely difficult to establish any relationship between studies as a consequence of no standard positivity criteria for PD-L1 expression, which involves the whole process, from chemical reactions machinery to dilutions of reactants and its reading interpretations. As seen in Table 12, there are different studies with different cutoffs for PD-L1 expression positivity.

Another important issue to be discussed is the feasibility of PD-L1 biomarker in order to be measured and analyzed in histopathological slides. Garon et al. noted PD-L1 deterioration in tumor samples cuts more than 6 months before staining [27]. According to Calles et al., there is deterioration of PD-L1 in blocks of more than three years [21]. In this study, staining was done less than a month after the cuts and due to this possible deterioration a lower cutoff of $5 \%$ was chosen.

A recent study showed that tumor microenvironment cells (including tumor cells, lymphocytes, and antigen presenting cells) do not express PD-L1 in a uniform way [36]. Smyth et al. argue that a successful cancer treatment must be precisely based on the stratification of tumor microenvironment and besides that it should not be restricted only to immune checkpoints but also to potentially involved cell types [42], as they are best studied and characterized.

Tumor microenvironment has a wide range of different cell types mainly represented by myeloid-derived suppressor cells, macrophages, dendritic cells, and T lymphocytes beyond tumor cells [43]. There is clearly a consensus that 
TABLE 8: PD-L1 expression in tumor cells and clinical data.

\begin{tabular}{|c|c|c|c|c|c|c|}
\hline \multirow{2}{*}{ Variable } & \multirow{2}{*}{ Categories } & \multicolumn{2}{|c|}{ Negative } & \multicolumn{2}{|c|}{ Positive } & \multirow{2}{*}{$p$ value } \\
\hline & & $N$ & $(\%)$ & $N$ & $(\%)$ & \\
\hline \multirow{3}{*}{ Histological type } & Adenocarcinoma & 68 & 68.7 & 40 & 59.7 & \multirow{3}{*}{0.412} \\
\hline & Squamous cell carcinoma & 28 & 28.3 & 25 & 37.3 & \\
\hline & Other & 3 & 3 & 2 & 3 & \\
\hline \multirow{2}{*}{ Tumor grade } & I and II & 50 & 62.5 & 31 & 64.6 & \multirow{2}{*}{0.813} \\
\hline & III & 30 & 37.5 & 17 & 35.4 & \\
\hline \multirow{4}{*}{ TNM staging } & $\mathrm{I}$ & 36 & 36.4 & 23 & 34.3 & \multirow{4}{*}{0.756} \\
\hline & II & 27 & 27.3 & 23 & 34.3 & \\
\hline & III & 26 & 26.3 & 14 & 20.9 & \\
\hline & IV & 10 & 10.1 & 7 & 10.4 & \\
\hline \multirow{2}{*}{ Neoadjuvant systemic treatment } & No & 86 & 86.9 & 61 & 91 & \multirow{2}{*}{0.407} \\
\hline & Yes & 13 & 13.1 & 6 & 9 & \\
\hline
\end{tabular}

TNM staging: TNM Classification of Malignant Tumours.

TABLE 9: PD-L1 expression in antigen presenting cells and clinical data.

\begin{tabular}{|c|c|c|c|c|c|c|}
\hline \multirow{2}{*}{ Variable } & \multirow{2}{*}{ Categories } & \multicolumn{2}{|c|}{ Negative } & \multicolumn{2}{|c|}{ Positive } & \multirow{2}{*}{$p$ value } \\
\hline & & $N$ & $(\%)$ & $N$ & $(\%)$ & \\
\hline \multirow{3}{*}{ Histological type } & Adenocarcinoma & 73 & 59.3 & 35 & 81.4 & \multirow{3}{*}{0.022} \\
\hline & Squamous cell carcinoma & 46 & 37.4 & 7 & 16.3 & \\
\hline & Others & 4 & 3.3 & 1 & 2.3 & \\
\hline \multirow{2}{*}{ Tumor grade } & I and II & 61 & 59.8 & 20 & 76.9 & \multirow{2}{*}{0.106} \\
\hline & III & 41 & 40.2 & 6 & 23.1 & \\
\hline \multirow{4}{*}{ TNM staging } & $\mathrm{I}$ & 42 & 34.1 & 17 & 39.5 & \multirow{4}{*}{0.416} \\
\hline & II & 41 & 33.3 & 9 & 20.9 & \\
\hline & III & 27 & 22 & 13 & 30.2 & \\
\hline & IV & 13 & 10.6 & 4 & 9.3 & \\
\hline \multirow{2}{*}{ Neoadjuvant systemic treatment } & No & 111 & 90.2 & 36 & 8.7 & \multirow{2}{*}{0.270} \\
\hline & Yes & 12 & 9.8 & 7 & 16.3 & \\
\hline
\end{tabular}

TNM staging: TNM Classification of Malignant Tumours.

TABLE 10: Multivariate analysis: PD-L1 expression in tumor cells.

\begin{tabular}{lccccc}
\hline \multirow{2}{*}{ Variable } & \multirow{2}{*}{ Categories } & \multirow{2}{*}{ OR } & \multicolumn{4}{c}{$95 \%$ CI } & \multirow{2}{*}{ LI value } \\
& & & LS & \\
\hline \multirow{3}{*}{ Smoking } & Never & 1 & & & 0.03 \\
& Active & 2.236 & 0.864 & 5.79 & 0.097 \\
& Past & 3.356 & 1.368 & 8.23 & 0.008 \\
\hline
\end{tabular}

TABLE 11: Multivariate analysis: PD-L1 positive IICs.

\begin{tabular}{lcccc}
\hline Variable & Categories & OR & $95 \%$ CI & $p$ value \\
\hline \multirow{3}{*}{ Smoking } & Never & 1 & & 0.090 \\
& Active & 0.525 & $0.212-1.297$ & 0.162 \\
& Past & 0.383 & $0.162-0.908$ & 0.029 \\
& Constant & 0.652 & & 0.198 \\
\hline
\end{tabular}

tumor microenvironment is a complex and dynamic structure so far as its presentation may vary for different time periods. The emergence of tumor cells leads to drastic changes that initiate immunity chronologically with an intrinsic induction of PD-L1 expression followed by adaptive immune tolerance and resistance to quantitative variations of various cell types, previously described [17].

4.2. Immunohistochemical Agreement between PD-L1 Expression in Individual Analysis and Collective Analysis (TMA). This study analysis showed a fair (low) agreement between the two methods of immunohistochemistry (individual and collective), for PD-L1 expression evaluation in lung tumors. The medical literature has pointed to the importance that lung tumor heterogeneity may have regarding PD-L1 expression in small biopsies when compared to surgical specimens.

Small isolated samples from a particular tumor region gathered by biopsy or punches for TMA construction, for example, cannot represent PD-L1 expression for the tumor as a whole. This expression cannot be generalized, because of its intrinsic regional variability. Immunohistochemistry assessment of slides covering a tumor in its largest possible area, with the largest represented diameters, seems to provide a more representative description of real PD-L1 expression in lung tumors. 
TABLE 12: Immunohistochemistry for PD-L1 in clinical studies.

\begin{tabular}{lccc}
\hline PD-L1 antibody & $\begin{array}{c}\text { Cutoff for positivity of PD-L1 } \\
\text { expression in tumor cell } \\
\text { membrane }\end{array}$ & Percentage of tumor samples expressing PD-L1 & Study reference \\
\hline $28-8$ & $5 \%$ & $49 \%$ & Grosso et al., JCO, 2013 [37] \\
R\&D B7-H1 & NR & $52 \%$ & Gatalica et al., CEBP, 2014 [38] \\
MIH1 & $>10 \%$ & $50 \%$ & Konishi et al., CCR, 2004 [39] \\
5 H1 & score & $21 \%$ (only CEC) et al., CCR, 2014 [30] \\
SP142 & $5 \%$ & $60 \%$ & Sun et al., JCO, 2014 [40] \\
NR & $1 \%$ & $50 \%$ & Garon et al., NEJM, 2015 [27] \\
$22 \mathrm{C} 3$ & $\geq 50 \%$ & $25 \%$ & Brahmer et al., NEJM, 2015 [33] \\
$28-8$ & $\geq 1 \%, \geq 5 \%, \geq 10 \%$ & $53 \%, 36 \%, 25 \%$ (only CEC) & Herbst et al., Nature, 2014 [41] \\
SP142 & $\geq 1 \%, \geq 5 \%, \geq 10 \%$ & $68 \%, 37 \%, 16 \%$ & $56 \%, 28 \%, 13 \%$ \\
SP142 & $\geq 1 \%, \geq 5 \%, \geq 10 \%$ & &
\end{tabular}

4.3. Correlation of PD-L1 Expression with Clinical and Demographic Data. In this study, tumors of patients with smoking history were more likely to positively express PD-L1 in tumor cells and they were also more likely to not express this biomarker in IICs. Although the influence of smoking in PD-L1 expression in tumor cells [21] has already been described, this is the first time that the possible influence of smoking in PD-L1 expression related to IICs is shown. Active smokers and former smokers were compared to nonsmokers (reference category after logistic regression). A possible explanation for the inverse relationship between smoking and PD-L1 expression in tumor cells versus IICs is the association between inflammatory proteins and such cell types with still unknown biological effects.

It is worth noting that changes in PD-L1 expression can also occur related to previous exposure to chemotherapy, a fact already demonstrated in urothelial carcinomas and lung cancer $[44,45]$. The small number of patients undergoing neoadjuvant chemotherapy prevented this analysis in the present study.

4.4. Survival Curves Analysis according to PD-L1 Expression. There was no statistical significance related to PD-L1 expression and overall survival as previously described. Other studies show apparently not to be a predictive or prognostic value regarding PP-L1 expression [27, 46, 47]. However, in a recently published meta-analysis, after analyzing five trials with 877 patients with non-small-cell lung cancer, Zhou et al. concluded that PD-L1 expression may be related to a worse prognosis [48]. Nonetheless, only one of these studies included western patients outside China. Variations in the choice of different cutoffs for expression of positivity and the type of tissue sample may have contributed to discrepant results.

In summary, this study shows that, in a population of patients with non-small-cell lung cancer, the pattern of PDL1 expression was heterogeneous, represented by two distinct cell types: the tumor cell (higher frequency) and IICs (lowest frequency). Positive PD-L1 expression was observed in $37.9 \%$ of tumor cells and in IICs of $24.3 \%$ of tumors.
TMA techniques (collective analysis) and conventional histological slides (individual analysis) showed fair agreement when they evaluated the immunoreactivity of PD-L1 expression in tumor cells (Kappa $=0.307$ ) and in antigen presenting cells $($ Kappa $=0.328)$ of patients with non-smallcell lung cancer, $p$ value $<0.001$, proving that TMA is not an adequate method to evaluate PD-L1 expression.

Former smokers had a higher PD-L1 expression in tumor cells when compared to those who had never smoked. In contrast, former smokers had a lower PD-L1 expression in IICs when compared to those who had never smoked. There was also no correlation between patterns of PD-L1 expression and survival in this population.

\section{Competing Interests}

The authors declare that they have no competing interests.

\section{Acknowledgments}

This work was supported by Grant CNPq (Conselho Nacional de Desenvolvimento Científico e Tecnológico) 447590/20146.

\section{References}

[1] R. L. Siegel, K. D. Miller, and A. Jemal, "Cancer statistics, 2016," CA: Cancer Journal for Clinicians, vol. 66, no. 1, pp. 7-30, 2016.

[2] Ministerio da Saúde, Estimativas 2016/2017 por Tipos de Câncer Rio de Janeiro, Instituto Nacional do Câncer, Rio de Janeiro, Brazil, 2015.

[3] R. J. Kelly, J. Gulley, and G. Giaccone, "Targeting the immune system in non-small-cell lung cancer: bridging the gap between promising concept and therapeutic reality," Clinical Lung Cancer, vol. 11, no. 4, pp. 228-237, 2010.

[4] D. M. Pardoll, "The blockade of immune checkpoints in cancer immunotherapy," Nature Reviews Cancer, vol. 12, no. 4, pp. 252264, 2012.

[5] A. H. Sharpe and G. J. Freeman, "The B7-CD28 superfamily," Nature Reviews Immunology, vol. 2, no. 2, pp. 116-126, 2002. 
[6] N. Karachaliou, M. G. Cao, C. Teixidó et al., "Understanding the function and dysfunction of the immune system in lung cancer: the role of immune checkpoints," Cancer Biology and Medicine, vol. 12, no. 2, pp. 79-86, 2015.

[7] Y. Ishida, Y. Agata, K. Shibahara, and T. Honjo, "Induced expression of PD-1, a novel member of the immunoglobulin gene superfamily, upon programmed cell death," EMBO Journal, vol. 11, no. 11, pp. 3887-3895, 1992.

[8] T. Shinohara, M. Taniwaki, Y. Ishida, M. Kawaichi, and T. Honjo, "Structure and chromosomal localization of the human PD-1 gene (PDCD1)," Genomics, vol. 23, no. 3, pp. 704-706, 1994.

[9] C. Blank, I. Brown, A. C. Peterson et al., "PD-L1/B7H-1 inhibits the effector phase of tumor rejection by $\mathrm{T}$ cell receptor (TCR) transgenic CD8+ T cells," Cancer Research, vol. 64, no. 3, pp. 1140-1145, 2004.

[10] C. Blank and A. Mackensen, "Contribution of the PD-L1/PD1 pathway to T-cell exhaustion: an update on implications for chronic infections and tumor evasion," Cancer Immunology, Immunotherapy, vol. 56, no. 5, pp. 739-745, 2007.

[11] M. J. Butte, V. Peña-Cruz, M.-J. Kim, G. J. Freeman, and A. H. Sharpe, "Interaction of human PD-L1 and B7-1," Molecular Immunology, vol. 45, no. 13, pp. 3567-3572, 2008.

[12] G. J. Freeman, A. J. Long, Y. Iwai et al., "Engagement of the PD-1 immunoinhibitory receptor by a novel B7 family member leads to negative regulation of lymphocyte activation," The Journal of Experimental Medicine, vol. 192, no. 7, pp. 1027-1034, 2000.

[13] H. Dong, G. Zhu, K. Tamada, and L. Chen, "B7-H1, a third member of the B7 family, co-stimulates T-cell proliferation and interleukin-10 secretion," Nature Medicine, vol. 5, no. 12, pp. 1365-1369, 1999.

[14] H. Dong, S. E. Strome, D. R. Salomao et al., "Tumor-associated B7-H1 promotes T-cell apoptosis: a potential mechanism of immune evasion," Nature Medicine, vol. 8, no. 8, pp. 793-800, 2002.

[15] S. L. Topalian, C. G. Drake, and D. M. Pardoll, "Targeting the PD-1/B7-H1(PD-L1) pathway to activate anti-tumor immunity," Current Opinion in Immunology, vol. 24, no. 2, pp. 207-212, 2012.

[16] Y. Iwai, M. Ishida, Y. Tanaka, T. Okazaki, T. Honjo, and N. Minato, "Involvement of PD-L1 on tumor cells in the escape from host immune system and tumor immunotherapy by PDL1 blockade," Proceedings of the National Academy of Sciences of the United States of America, vol. 99, no. 19, pp. 12293-12297, 2002.

[17] M. W. L. Teng, S. F. Ngiow, A. Ribas, and M. J. Smyth, "Classifying cancers based on T-cell infiltration and PD-L1," Cancer Research, vol. 75, no. 11, pp. 2139-2145, 2015.

[18] Z. Chen, J. Mei, L. Liu et al., "PD-L1 expression is associated with advanced non-small cell lung cancer," Oncology Letters, vol. 12, no. 2, pp. 921-927, 2016.

[19] K. Takada, T. Okamoto, F. Shoji et al., "Clinical significance of PD-L1 protein expression in surgically resected primary lung adenocarcinoma," Journal of Thoracic Oncology, 2016.

[20] Y. J. Cha, H. R. Kim, C. Y. Lee, B. C. Cho, and H. S. Shim, “Clinicopathological and prognostic significance of programmed cell death ligand-1 expression in lung adenocarcinoma and its relationship with p53 status," Lung Cancer, vol. 97, pp. 73-80, 2016.

[21] A. Calles, X. Liao, L. M. Sholl et al., "Expression of PD-1 and its ligands, PD-L1 and PD-L2, in smokers and never smokers with KRAS-mutant lung cancer," Journal of Thoracic Oncology, vol. 10, no. 12, pp. 1726-1735, 2015.
[22] M. Shimoji, S. Shimizu, K. Sato et al., "Clinical and pathologic features of lung cancer expressing programmed cell death ligand 1 (PD-L1)," Lung Cancer, vol. 98, pp. 69-75, 2016.

[23] P. Waterhouse, J. M. Penninger, E. Timms et al., "Lymphoproliferative disorders with early lethality in mice deficient in Ctla-4," Science, vol. 270, no. 5238, pp. 985-988, 1995.

[24] L. L. Carter, L. A. Fouser, J. Jussif et al., "PD-1:PD-L inhibitory pathway affects both CD4+ and CD8+ T cells and is overcome by IL-2," European Journal of Immunology, vol. 32, no. 3, pp. 634-643, 2002.

[25] G. Toyokawa, K. Takada, N. Haratake et al., "Favorable diseasefree survival associated with programmed death ligand 1 expression in patients with surgically resected small-cell lung cancer," Anticancer Research, vol. 36, no. 8, pp. 4329-4336, 2016.

[26] S. E. Strome, H. Dong, H. Tamura et al., "B7-H1 blockade augments adoptive T-cell immunotherapy for squamous cell carcinoma," Cancer Research, vol. 63, no. 19, pp. 6501-6505, 2003.

[27] E. B. Garon, N. A. Rizvi, R. Hui et al., "Pembrolizumab for the treatment of non-small-cell lung cancer," The New England Journal of Medicine, vol. 372, no. 21, pp. 2018-2028, 2015.

[28] F. Passiglia, G. Bronte, V. Bazan et al., "PD-L1 expression as predictive biomarker in patients with NSCLC: a pooled analysis," Oncotarget, vol. 7, no. 15, pp. 19738-19747, 2016.

[29] E. M. G. Marcella Callea, M. Gupta, S. C. Cheng et al., "PD-L1 expression in primary clear cell renal cell carcinomas (ccRCCs) and their metastases," Journal of Clinical Oncology, vol. 32, supplement 5, abstract 4585, 2014.

[30] A. M. Marti, P. Martinez, A. Navarro et al., "Concordance of PD-L1 expression by different immunohistochemistry (IHC) definitions and in situ hybridization (ISH) in squamous cell carcinoma (SCC) of the lung," Journal of Clinical Oncology, vol. 32, supplement 5, abstract 7569, 2014, Proceedings of the 2014 ASCO Annual Meeting.

[31] G. Schmid-Bindert and T. Jiang, "First-line nivolumab (antiPD-1) monotherapy in advanced NSCLC: the story of immune checkpoint inhibitors and 'the sorcerers apprentice," Translational Lung Cancer Research, vol. 4, no. 3, pp. 215-216, 2015.

[32] A. D'Incecco, M. Andreozzi, V. Ludovini et al., "PD-1 and PD-L1 expression in molecularly selected non-small-cell lung cancer patients," British Journal of Cancer, vol. 112, no. 1, pp. 95-102, 2015.

[33] J. Brahmer, K. L. Reckamp, P. Baas et al., "Nivolumab versus docetaxel in advanced squamous-cell non-small-cell lung cancer," The New England Journal of Medicine, vol. 373, no. 2, pp. 123-135, 2015.

[34] M.-Y. Kim, J. Koh, S. Kim, H. Go, Y. K. Jeon, and D. H. Chung, "Clinicopathological analysis of PD-L1 and PD-L2 expression in pulmonary squamous cell carcinoma: comparison with tumorinfiltrating T cells and the status of oncogenic drivers," Lung Cancer, vol. 88, no. 1, pp. 24-33, 2015.

[35] V. Velcheti, K. A. Schalper, D. E. Carvajal et al., "Programmed death ligand-1 expression in non-small cell lung cancer," Laboratory Investigation, vol. 94, no. 1, pp. 107-116, 2014.

[36] K. M. Kerr, M.-S. Tsao, A. G. Nicholson, Y. Yatabe, I. I. Wistuba, and F. R. Hirsch, "Programmed death-ligand 1 immunohistochemistry in lung cancer: in what state is this art?" Journal of Thoracic Oncology, vol. 10, no. 7, pp. 985-989, 2015.

[37] "Association of tumor PD-L1 expression and immune biomarkers with clinical activity in patients (pts) with advanced solid tumors treated with nivolumab (anti-PD-1; BMS-936558; 
ONO-4538)," in Proceedings of the ASCO Annual Meeting, J. Grosso, C. E. Horak, D. Inzunza et al., Eds., 2013.

[38] Z. Gatalica, C. Snyder, T. Maney et al., "Programmed cell death 1 (PD-1) and its ligand (PD-L1) in common cancers and their correlation with molecular cancer type," Cancer Epidemiology Biomarkers and Prevention, vol. 23, no. 12, pp. 2965-2970, 2014.

[39] J. Konishi, K. Yamazaki, M. Azuma, I. Kinoshita, H. DosakaAkita, and M. Nishimura, "B7-H1 expression on non-small cell lung cancer cells and its relationship with tumor-infiltrating lymphocytes and their PD-1 expression," Clinical Cancer Research, vol. 10, no. 15, pp. 5094-5100, 2004.

[40] "PD-L1 expression and survival in patients with non-small cell lung cancer (NSCLC) in Korea," in Proceedings of the ASCO Annual Meeting, J.-M. Sun, W. Zhou, Y.-L. Choi et al., Eds., 2014.

[41] R. S. Herbst, J.-C. Soria, M. Kowanetz et al., "Predictive correlates of response to the anti-PD-L1 antibody MPDL3280A in cancer patients," Nature, vol. 515, no. 7528, pp. 563-567, 2014.

[42] M. J. Smyth, S. F. Ngiow, A. Ribas, and M. W. L. Teng, "Combination cancer immunotherapies tailored to the tumour microenvironment," Nature Reviews Clinical Oncology, vol. 13, no. 3, pp. 143-158, 2016.

[43] S. P. Kerkar and N. P. Restifo, "Cellular constituents of immune escape within the tumor microenvironment," Cancer Research, vol. 72, no. 13, pp. 3125-3130, 2012.

[44] A. S. McDaniel, A. Alva, T. Zhan et al., "Expression of PDL1 (B7H1) before and after neoadjuvant chemotherapy in urothelial carcinoma," European Urology Focus, vol. 1, no. 3, pp. 265-268, 2016.

[45] K. Lin, J. Cheng, T. Yang, Y. Li, and B. Zhu, "EGFR-TKI downregulates PD-L1 in EGFR mutant NSCLC through inhibiting NF- $\kappa$ B," Biochemical and Biophysical Research Communications, vol. 463, no. 1-2, pp. 95-101, 2015.

[46] E. Brambilla, Ed., The World Conference on Lung Cancer, PD1/PDL1 Biomarker Strategies, Denver, Colo, USA, 2015.

[47] H. S. Kim, J. Y. Lee, S. H. Lim et al., "Association between PD-L1 and HPV status and the prognostic value of PD-L1 in oropharyngeal squamous cell carcinoma," Cancer Research and Treatment, vol. 48, no. 2, pp. 527-536, 2016.

[48] Z. J. Zhou, P. Zhan, and Y. Song, "PD-L1 over-expression and survival in patients with non-small cell lung cancer: a metaanalysis," Translational Lung Cancer Research, vol. 4, no. 2, pp. 203-208, 2015. 


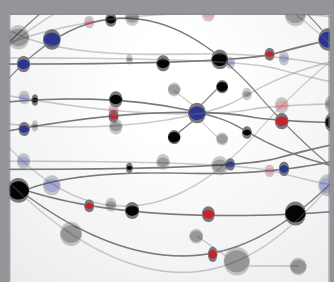

The Scientific World Journal
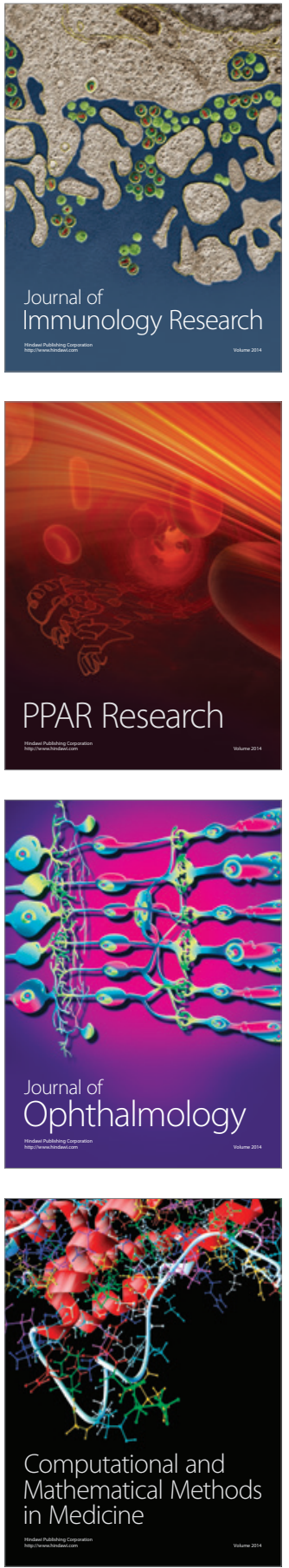

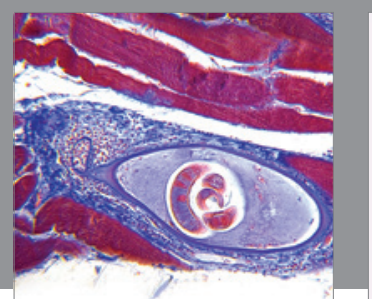

Gastroenterology Research and Practice

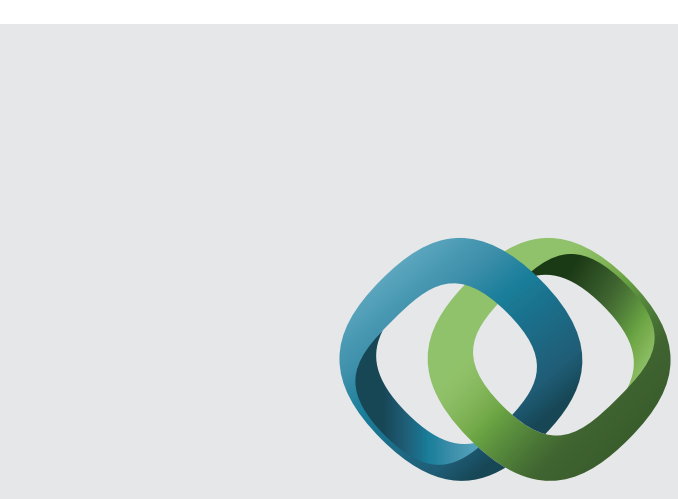

\section{Hindawi}

Submit your manuscripts at

http://www.hindawi.com
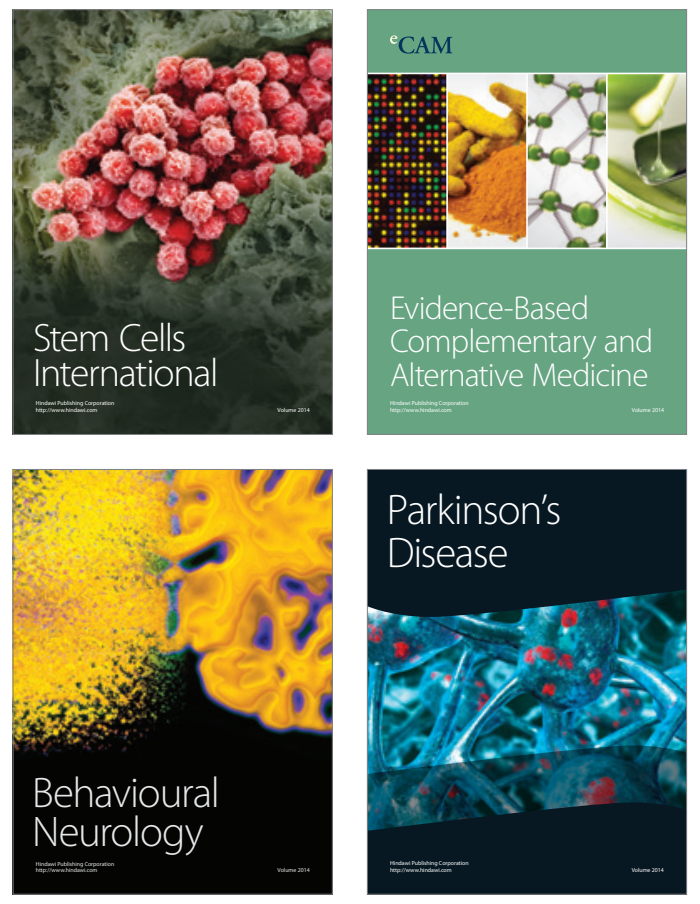
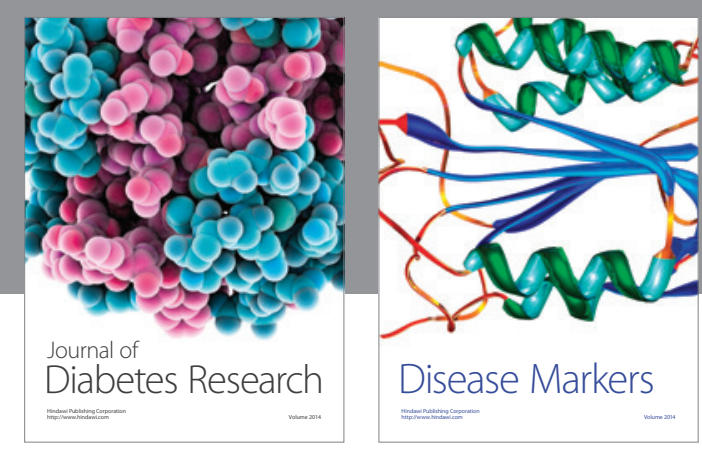

Disease Markers
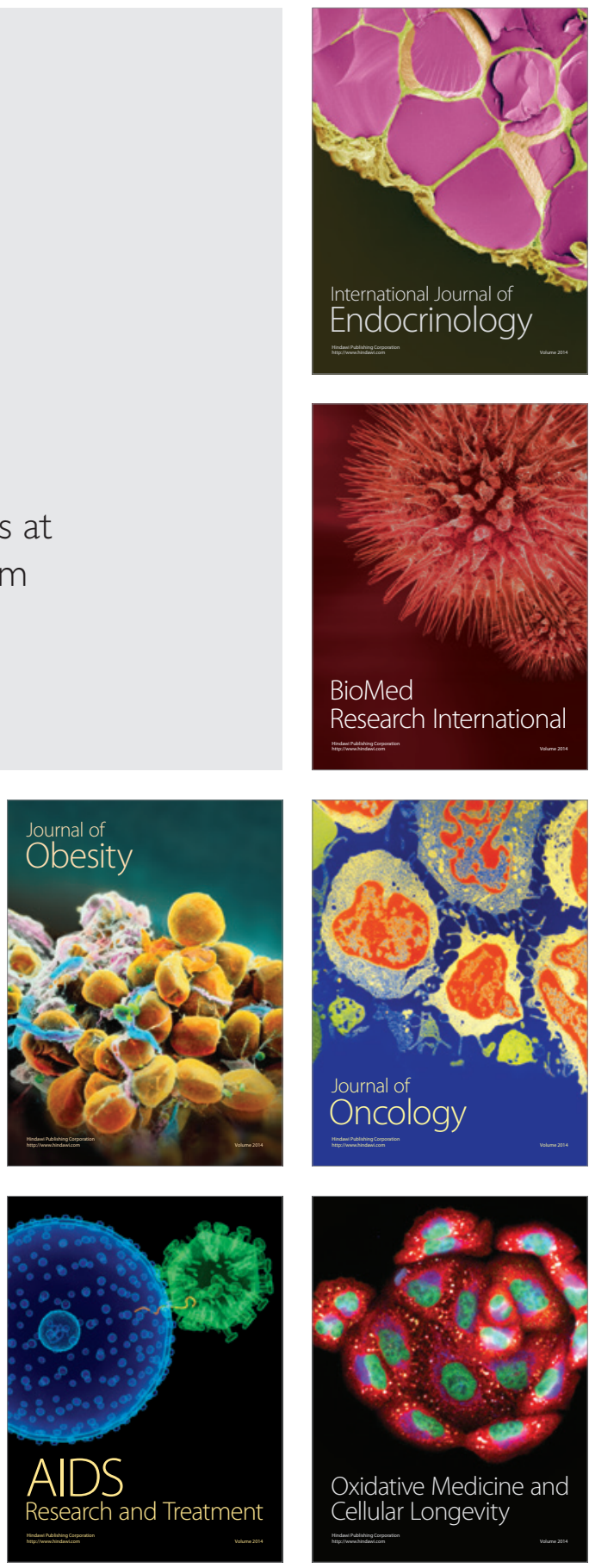